\title{
Morphologic Response of the Mucosa of Human Small Intestine to X-Ray Exposure *
}

\author{
Jerry S. Trier † and Thomas H. Browning \\ (From the Gastroenterology Research Laboratory, Veterans Administration Hospital, and the \\ Department of Medicine, University of Wisconsin, Madison, Wis.)
}

Prolonged and repeated exposure to sublethal doses of total body irradiation induce significant morphologic changes in the mucosa of the small intestine of laboratory animals. These changes include decreased mitosis in the intestinal crypts, necrosis of crypt epithelial cells, and decreased height of crypts and villi (2-5).

In man, submucosal fibrosis $(6,7)$ and mucosal and submucosal lymphangiectasia ( 8 ) have been noted together with gastrointestinal malabsorption

\footnotetext{
* Submitted for publication August 26, 1965 ; accepted October 28, 1965.

Presented in part at the Joint Gastroenterology Subsection Meeting of the American Society for Clinical Investigation and the American Federation for Clinical Research May 2, 1965, Atlantic City, N. J. (1).

Supported in part by grant AM- 08379 from the $\mathrm{Na}$ tional Institute of Arthritis and Metabolic Diseases, National Institutes of Health, Bethesda, Md.

$\dagger$ Address requests for reprints to Dr. Jerry S. Trier, Veterans Administration Hospital, 2500 Overlook Terr., Madison, Wis. 53705.
}

(6-9) as late complications after X-ray therapy to the abdomen. However, very little is known about the immediate morpholgic response of the mucosa of human small intestine to therapeutically employed doses of $\mathrm{X}$ ray. This is surprising since $\mathrm{X}$-ray therapy to the abdomen with resultant exposure of small bowel to ionizing radiation is commonly utilized for the clinical treatment of a variety of intra-abdominal and retroperitoneal malignancies. Furthermore, it is well known that gastrointestinal symptoms including nausea, vomiting, and diarrhea may accompany such X-ray treatment. We therefore felt that a prospective sequential study of the morphology of the small intestinal mucosa of man exposed to therapeutic abdominal $\mathrm{X}$-irradiation would be of interest.

\section{Methods}

Nine patients who received X-ray therapy to the abdomen were selected for study. Pertinent clinical data and details of their X-ray treatment are summarized in

TABLE I

Clinical data concerning patients studied

\begin{tabular}{|c|c|c|c|c|c|c|c|c|}
\hline Patient & Age & Diagnosis & $\begin{array}{l}\text { Abdominal } \\
\text { X-ray } \\
\text { depth } \\
\text { dose }\end{array}$ & $\begin{array}{l}\text { Num- } \\
\text { ber of } \\
\text { treat- } \\
\text { ments }\end{array}$ & $\begin{array}{l}\text { Dura- } \\
\text { tion of } \\
\text { therapy }\end{array}$ & $\begin{array}{l}\text { Site of } \\
\text { therapy }\end{array}$ & $\begin{array}{l}\text { Weight } \\
\text { change }\end{array}$ & $\begin{array}{c}\text { Symptoms } \\
\text { during } \\
\text { therapy }\end{array}$ \\
\hline & years & & röntgens & & days & & pounds & \\
\hline 1 & 29 & $\begin{array}{c}\text { Hodgkin's } \\
\text { disease }\end{array}$ & 3,000 & 18 & 24 & $\begin{array}{l}\text { Left upper } \\
\text { quadrant }\end{array}$ & +6 & \\
\hline 2 & 31 & $\begin{array}{c}\text { Hodgkin's } \\
\text { disease }\end{array}$ & 2,000 & 14 & 19 & Periumbilical & -7 & Mild nausea \\
\hline 3 & 27 & $\begin{array}{c}\text { Hodgkin's } \\
\text { disease }\end{array}$ & 2,000 & 14 & 24 & Periumbilical & -15 & $\begin{array}{c}\text { Nausea and } \\
\text { vomiting }\end{array}$ \\
\hline 4 & 29 & $\begin{array}{c}\text { Hodgkin's } \\
\text { disease }\end{array}$ & 2,000 & 14 & 18 & Periumbilical & +1 & Mild nausea \\
\hline 5 & 69 & Lymphosarcoma & 2,300 & 16 & 22 & Epigastric & -1 & . \\
\hline 6 & 37 & Seminoma & 3,300 & 24 & 28 & $\begin{array}{l}\text { Left upper } \\
\text { quadrant }\end{array}$ & +1 & \\
\hline 7 & 74 & $\begin{array}{l}\text { Intractable } \\
\text { duodenal ulcer }\end{array}$ & 2,000 & 14 & 20 & $\begin{array}{l}\text { Left upper } \\
\text { quadrant }\end{array}$ & -3 & \\
\hline $8 *$ & 70 & Lymphosarcoma & 2,300 & 14 & 22 & Periumbilical & -1 & \\
\hline $9 *$ & 54 & $\begin{array}{l}\text { Ovarian } \\
\text { carcinoma }\end{array}$ & 3,200 & 24 & 30 & Pelvic & +1 & \\
\hline
\end{tabular}

* Small bowel biopsies obtained distant from field of irradiation. 
Table I. X-ray therapy was administered to alternate anterior and posterior abdominal ports with a $1,000 \mathrm{kv}$ therapy unit in fractional skin doses of 150 to 300 röntgens (R) for 5 or 6 days per week. None of the patients were acutely or critically ill when first studied. One patient's condition (no. 3) deteriorated significantly during the study; the other patients remained ambulatory throughout the study.

A total of 104 peroral duodenal or jejunal biopsies was obtained serially from seven patients from small bowel within the irradiated field. Biopsies from five of these patients were obtained before, during, and after X-ray therapy; biopsies in the other two were obtained only during the course of X-ray therapy. In addition, 10 biopsies were obtained from jejunum outside of the field of irradiation from each of two other patients before, during, and after therapy. One of these patients received abdominal irradiation (no. 8), and the other received pelvic irradiation (no. 9). In both of these patients the region of the duodenojejunal junction from which biopsies were obtained was over $10 \mathrm{~cm}$ from the field of irradiation.

Patients were deprived of food but allowed water ad libitum for 12 hours before biopsy. All biopsies were obtained under fluoroscopic control with a multipurpose biopsy tube (10). Biopsies for light microscopic study were carefully oriented immediately after removal from the biopsy capsule, fixed in Bouin's solution, and embedded in paraffin. Four- $\mu$ serial sections were cut parallel to the long axes of the villi. Sections were stained with hematoxylin and eosin and with the Fuelgen technique.

To quantitate mitotic activity in the crypts, mitotic figures were counted in every third section of serially sectioned biopsies (11). Only those crypt sections in which the lumen was seen and in which orientation was good were counted. Mitotic figures in at least 200 such crypt profiles were counted in each biopsy, and the results were expressed as number of mitoses per $100 \mathrm{crypt}$ sections.

Changes in epithelial surface area were evaluated by quantitating epithelial surface length of each suitable biopsy utilizing Rubin, Brandborg, Phelps, and Taylor's modification (12) of Chalkley's random point technique (13). A mold-counting grid with 25 grid line intersects was inserted into one of the microscope oculars. With a well-oriented biopsy section centered in the microscopic field, the number of intersect points overlying epithelial cells was counted. This was repeated in a random fashion 20 times for each biopsy, and the total count was used as a measure of the epithelial surface of the biopsy. The accuracy of this technique has been shown to approach the accuracy of linear surface measurement of photographs or tracings of well-oriented biopsies (12).

Eight biopsies from three patients were studied with the electron microscope. The biopsies for electron microscopy were placed in toto into chilled chrome-osmium tetroxide (14) within 1 minute after excision. After 4 minutes, the biopsies were cut parallel to the plane of the villi into $1-\mathrm{mm}$ strips and returned to the fixative for 1 hour. The tissue slices were post-fixed in $10 \%$ neutral isotonic formol for 1 hour, rapidly dehydrated in graded strengths of ethyl alcohol, and embedded in epoxy resin by the method of Luft (15). The embedded tissue slices were cut out of the epoxy block and halved, and each half was carefully oriented and mounted with epoxy cement

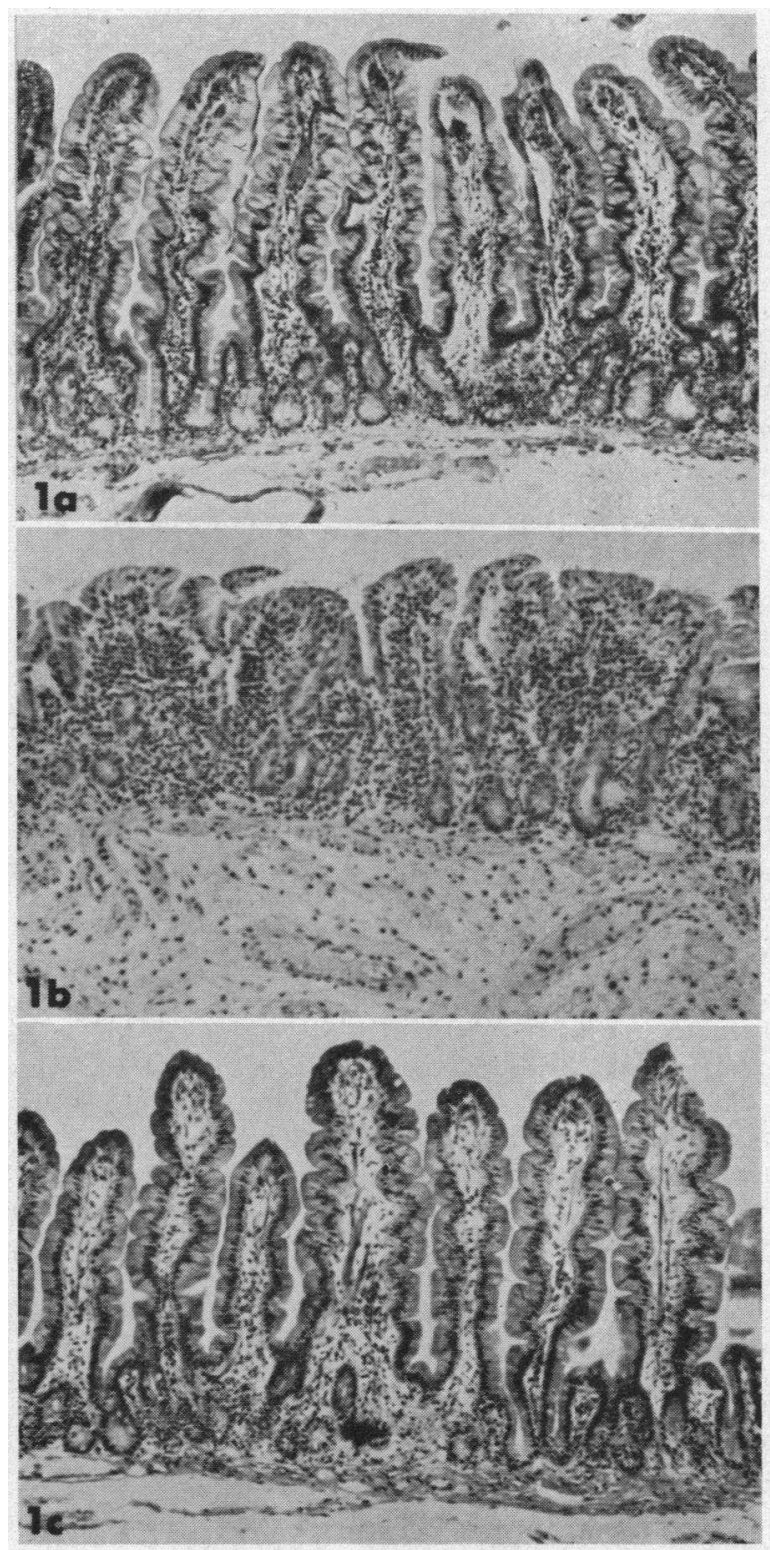

Fig. 1. Three biopsies from the duodenojejunal JUNCTION OF A PATIENT UNDERGOING ABDOMINAL X-RAY THERAPY. a) Before treatment, the villous architecture is normal. b) After 3,300 röntgens ( $R$ ) X-ray therapy, the villi are shortened, there is increased infiltration of the lamina propria with inflammatory cells, and submucosal edema is present. c) Twelve days after cessation of therapy, villous architecture has returned to normal. Hematoxylin and eosin, $75 \times$. 


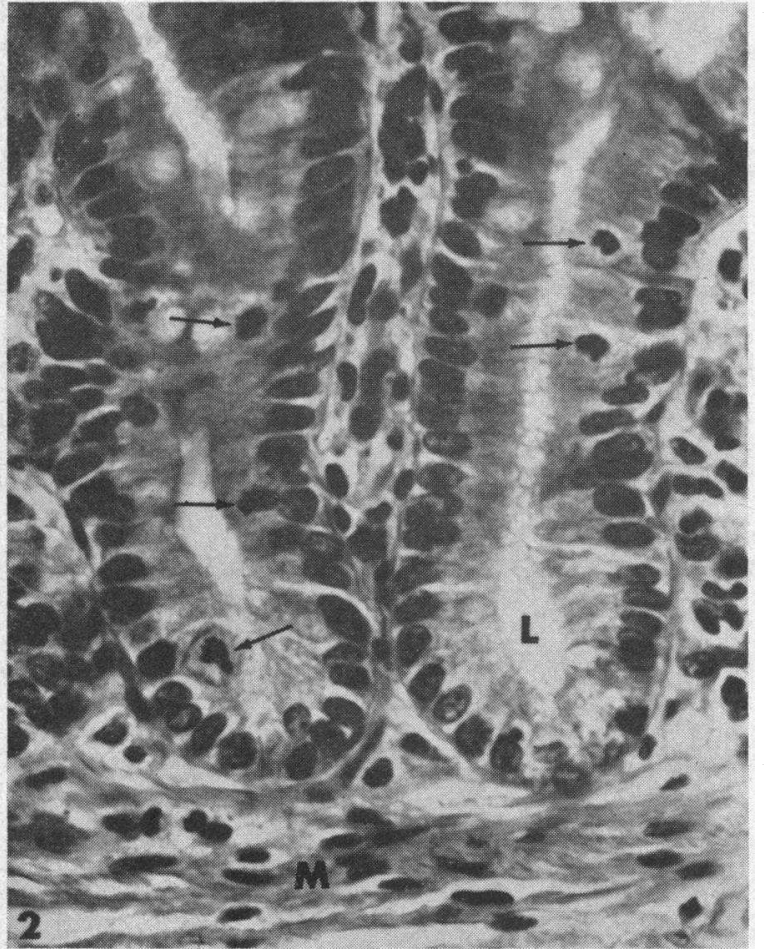

Fig. 2. NoRMal CRYPT EPITHELIUM FROM A PRETREATMENT BIOPSY. Epithelial cells are columnar with basally located nuclei. $\mathrm{L}=$ crypt lumina, $\mathrm{M}=$ muscularis mucosa, and arrows $=$ mitoses. Hematoxylin and eosin, $500 \times$.

on a short aluminum rod machined to fit the microtome chuck. Sections parallel to the plane of the villi were cut $1 \mu$ thick with glass knives, mounted on glass slides, and stained with toluidine blue (16) for light microscopic studies. From these "thick" sections, well-fixed, untraumatized areas on villi and in crypts were selected for further study with the electron microscope. Tissue blocks were suitably trimmed to these areas, and thin sections were cut with an LKB microtome using diamond knives. Thin sections were mounted on carbon-coated copper mesh grids and were stained with lead salts using Luft's modification (17) of Millonig's technique (18). Specimens were studied with an RCA EMU-3G electron microscope.

\section{Results}

During the first week of X-ray exposure, the villous architecture of the irradiated small intestinal mucosa appeared unchanged at low magnification. During the second week, some shortening of villi was evident. This increased with further irradiation, and by the end of therapy, villous shortening had progressed so that there was striking altera- tion of mucosal architecture compared to pretreatment biopsies (Figure 1, a and b). Not only were the villi of the irradiated bowel shortened compared to the long, delicate, slender villi of the control biopsies, but the total thickness of the mucosa was reduced considerably.

An increase in cellular elements per unit area of lamina propria was also noted at low magnification within a week after the start of therapy. This too increased with further X-ray exposure (compare Figure 1, $a$ and $b$ ). Infiltration of the submucosa with increased numbers of lymphocytes and plasma cells was regularly noted after 3 or more weeks of irradiation exposure (Figure 1b). The submucosa of these biopsies contained much structurally homogeneous eosinophilic material suggestive of edema fluid.

When the biopsies were studied with higher magnification, significant changes were present in the crypt epithelium during the first week of irradiation therapy. Within 12 hours after the first $\mathrm{X}$-ray treatment, the number of mitoses in the

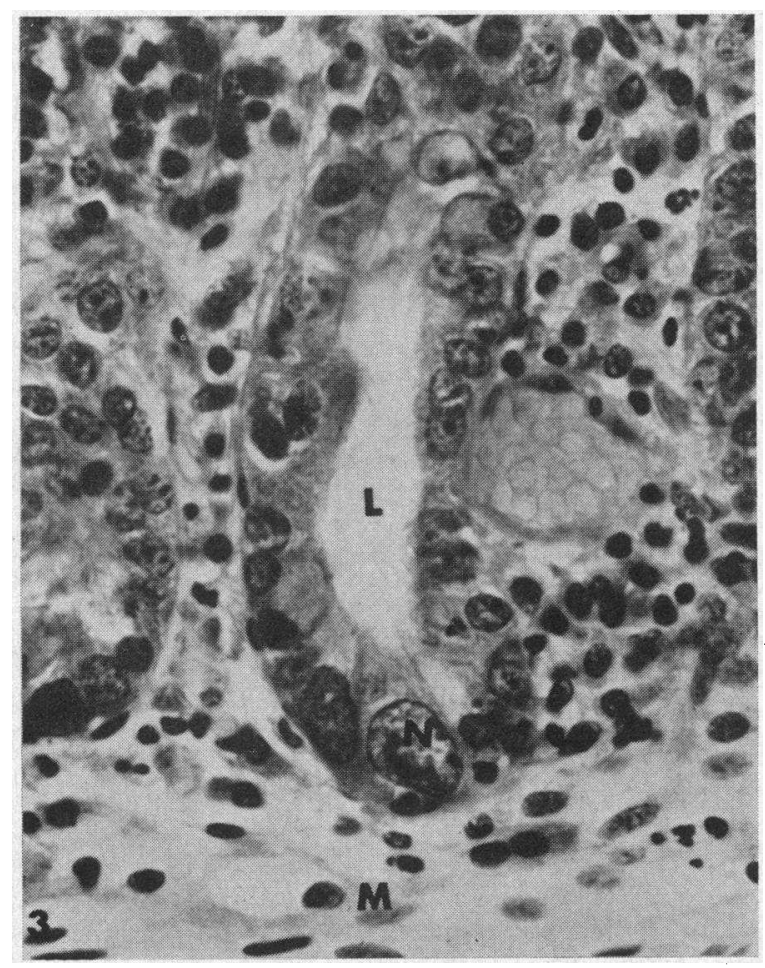

Fig. 3. CRYPT epithelium FROM the SAME PATIENT AS Figure 2 after 3,300 R. Most epithelial cells are cuboidal, and many contain huge nuclei $(N)$. Hematoxylin and eosin, $500 \times$. 
crypts was greatly reduced compared to base-line levels. Mitoses decreased progressively during the first week of therapy and then remained at low levels until treatment was stopped (Figures 2, 3). In those mitoses present during treatment, distinct morphologic abnormalities such as chromosomal bridges and chromosomal clumping were seen in many. Discrete, small, spherical inclusion bodies containing material that stained intensely with the Fuelgen technique were frequently seen within the cytoplasm of the undifferentiated crypt cells during the first week of therapy but were uncommon thereafter (Figure 4). These bodies appeared identical to those previously noted in the undifferentiated crypt cells after exposure to radiomimetic drugs, and they probably represent fragments of disintegrating epithelial cells (11).

With increasing exposure, the height of the undifferentiated crypt epithelial cells decreased progressively, whereas their width increased until the cells were cuboidal or even squamous in appearance compared to the pretreatment columnar shape (Figures 2,3). Huge polyploid hyperchromatic nuclei in large megaloblastic cells were common in the crypts after the first week of therapy, and virtually no normal-appearing undifferentiated crypt cells could be seen after 3 weeks of therapy

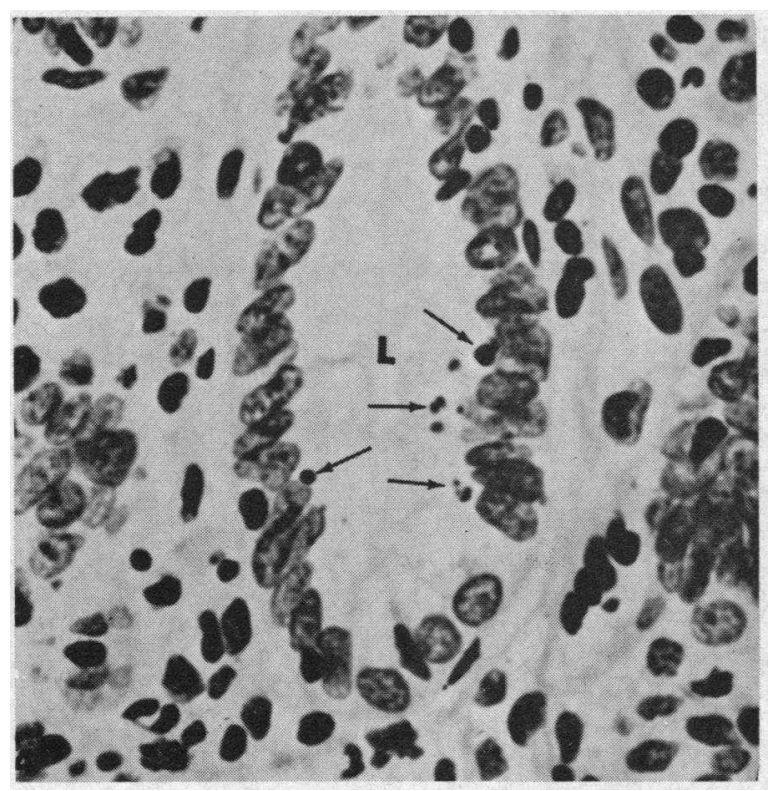

Fig. 4. A tYPiCAL JEJUNAL CRYPT 20 HOURS AFter EXPOSURE TO A SINGLE 250-R DOSE OF X RAY. DNA-containing Fuelgen positive inclusions (arrows) are seen in the cytoplasm of some cells. Fuelgen-fast green, $550 \times$.

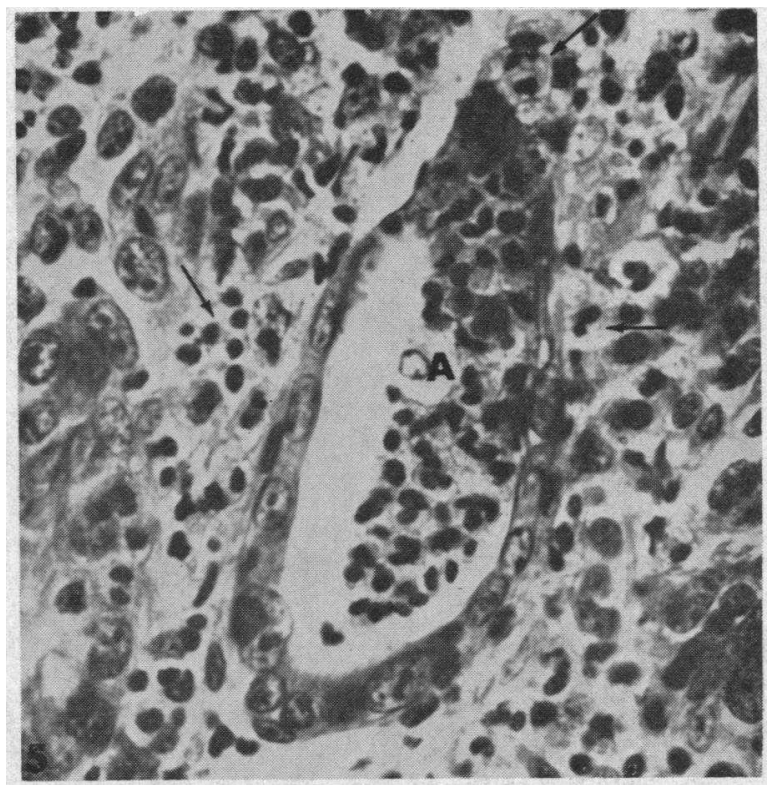

Fig. 5. A CRYPT ABSCESS (A) IN A BIOPSY OF SMALI BOWEL EXPOSED TO 3,300 R X RAY. The surrounding epithelial cells are flattened and contain megaloblastic nuclei. The crypt abscess is composed primarily of polymorphonuclear leukocytes, which (arrows) are also seen in the lamina propria. Hematoxylin and eosin, $500 \times$.

(Figure 3). Paneth cells appeared diminished in number, but those present appeared normal by light microscopic criteria. Goblet cells were seen in normal numbers in the crypts and on the villi but were decreased in height and increased in width during peak histologic reaction to radiation.

As the villi decreased in height during the second to fourth week of therapy, the villous absorptive cells also assumed a cuboidal shape, decreasing in height and increasing strikingly in width. Megalocytosis of the absorptive cells was observed in all biopsies obtained during the third and fourth weeks of therapy. In all biopsies, the epithelial surface remained intact; discontinuities were not observed.

The number of cells in the lamina propria increased as therapy progressed. Plasma cells were the most abundant cell type, but eosinophils and mast cells were also noted. Lymphocytes, abundant in control biopsies, were infrequently seen in irradiated bowel, as one might expect because of their extreme radiosensitivity (19). During the third and fourth weeks, accumulations of polymorphonuclear leukocytes were observed in biopsies of four of the seven patients (Figure 5 ). In 
some areas, the inflammatory reaction was sufficiently severe to result in crypt abscess formation (Figure 5). These microabscesses were composed largely of polymorphonuclear leukocytes although cellular debris, probably of epithelial origin, were also noted in the crypt lumina.

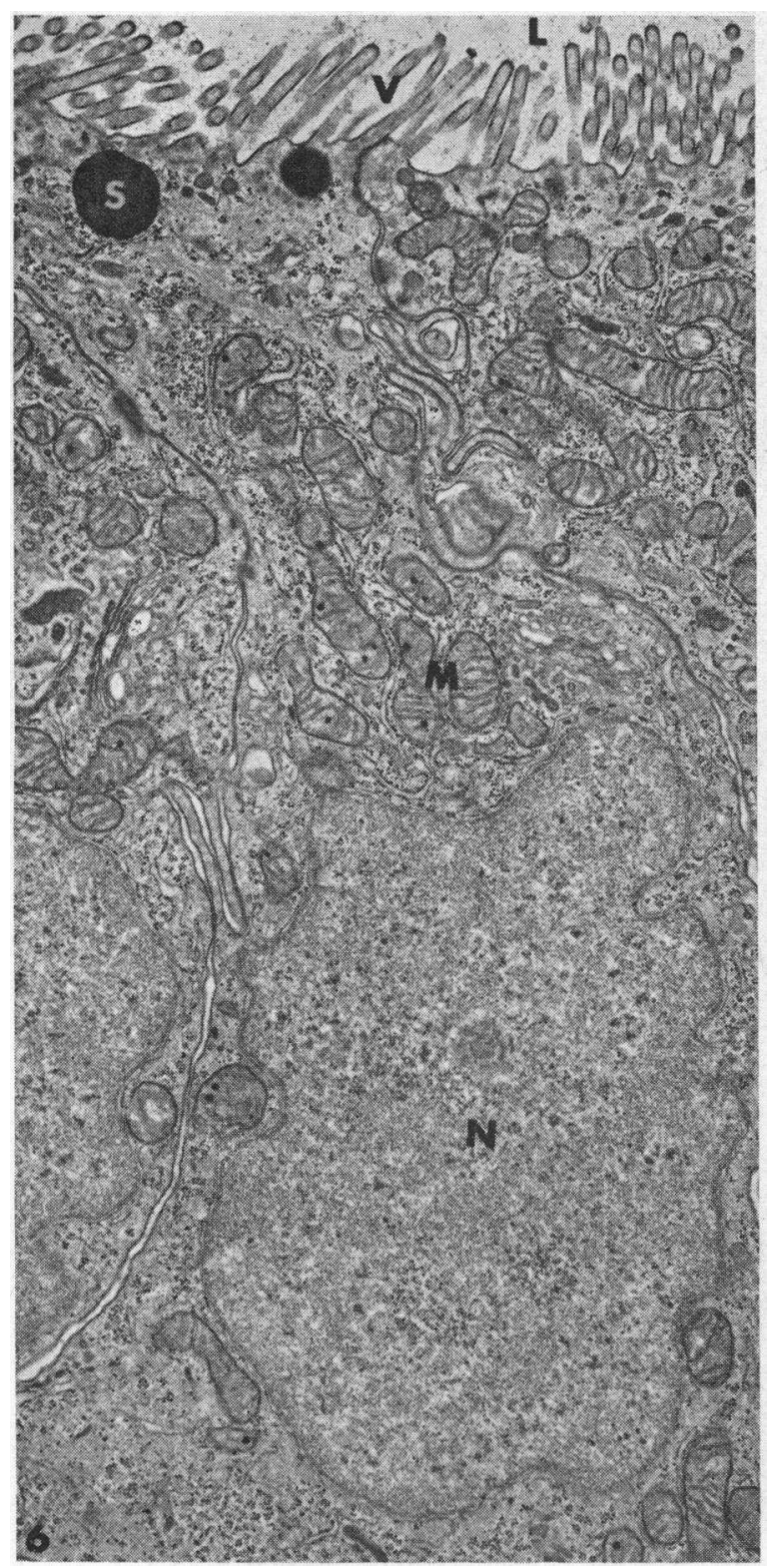

Fig. 6. A REPRESENTATIVE NORMAL UNDIFFERENTIATED CRYPT CELL FROM A PRETREATMENT BIOPSY. Note the wellformed microvilli (V) and compact cytoplasm. $\mathrm{N}=$ nucleus, $\mathrm{M}=$ mitochondria, and $\mathrm{S}=$ secretory granules $(12,000 \times)$.
Electron microscopic study of biopsies obtained during peak histologic reaction to X-ray therapy confirmed the light microscopic findings and also revealed additional cytologic damage of the epithelial cells.

The proliferating undifferentiated crypt cells

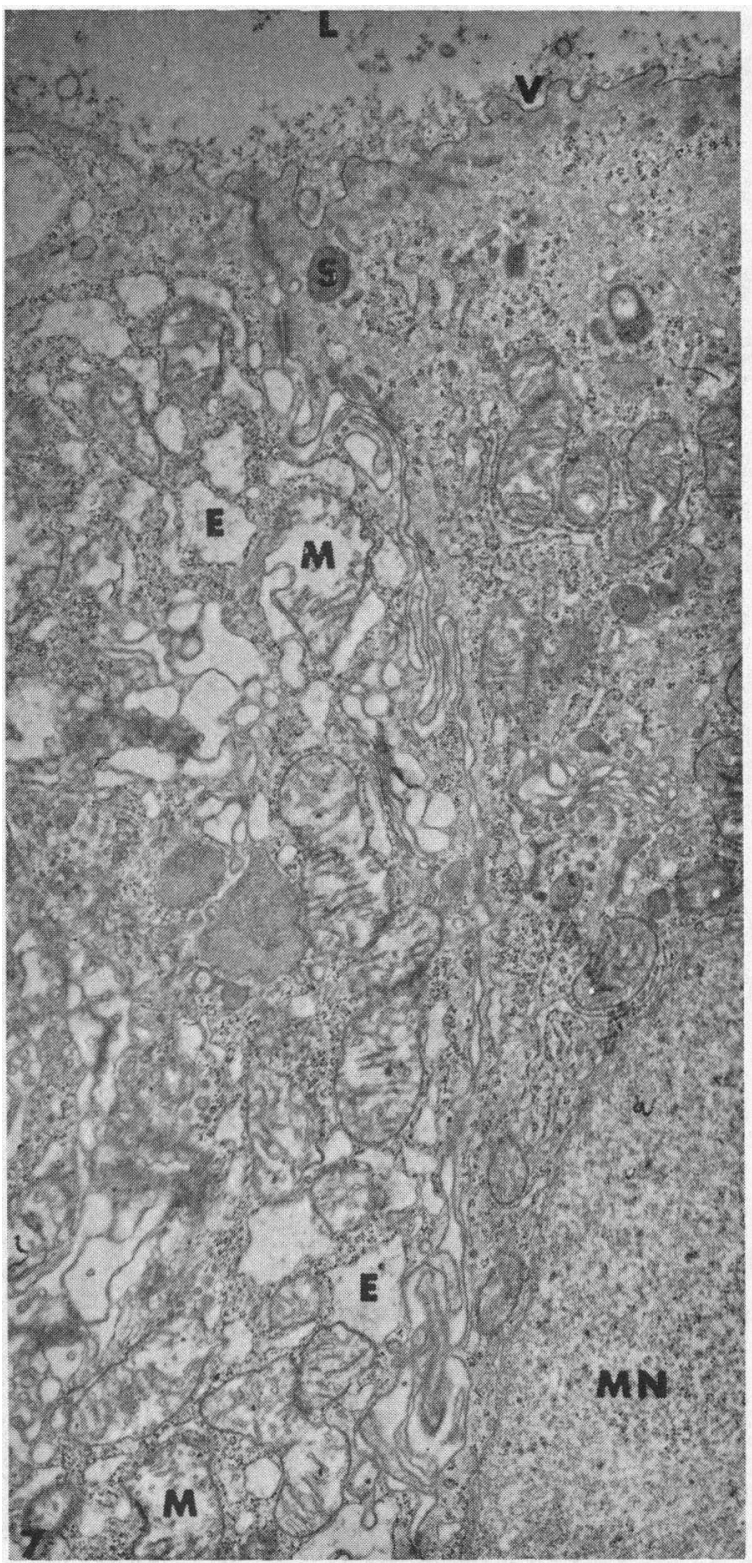

Fig. 7. UNDIFFERENTIATEd CRYPT CELLS FROM THE SAME patient as Figure 6 after 3,300 R. Note the marked shortening and irregularity of the microvilli. The cell to the left is more severely damaged; swollen mitochondria (M) and abnormally dilated endoplasmic reticulum (E) are apparent. $\mathrm{MN}$ is a portion of a megaloblastic nucleus. $(12,000 \times$.) 
were the most severely damaged epithelial cell type. The microvilli of these cells were very short and irregular compared to those seen in pretreatment control biopsies (Figures 6,7). In addition, there was marked dilatation of mitochondria and endoplasmic reticulum in many cells (Figure 7). The undifferentiated cell secretory granules, though present, were greatly reduced in number. The degree of cytoplasmic damage was not equal in all crypt cells (Figure 7), but no normal undifferentiated cells were seen in biopsies obtained after 3 or more weeks of X-ray therapy. Spotty and less consistent cytoplasmic damage of the endoplasmic reticulum and mitochondria of the other epithelial cell types of the crypt (Paneth, enterochromaffin, and goblet cells) was noted after radiation. Large cell remnants were commonly seen lying free within the crypt lumen (Figure 8). The structure of many of these suggested an epithelial origin.

Spotty, nonspecific cytoplasmic damage was also evident among villous absorptive cells in biopsies obtained 3 or more weeks after the start of X-ray treatment. Dilatation of the endoplasmic reticulum and vacuolization of the mitochondria were the most predominant and consistent findings (Figures 9, 10). In addition, it was noted that sections of nuclei of irradiated absorptive cells regularly displayed huge nucleoli. The periphery of the nucleus often appeared scalloped throughout its circumference (Figure 10). These were not observed in absorptive cell nuclei from control biopsies.

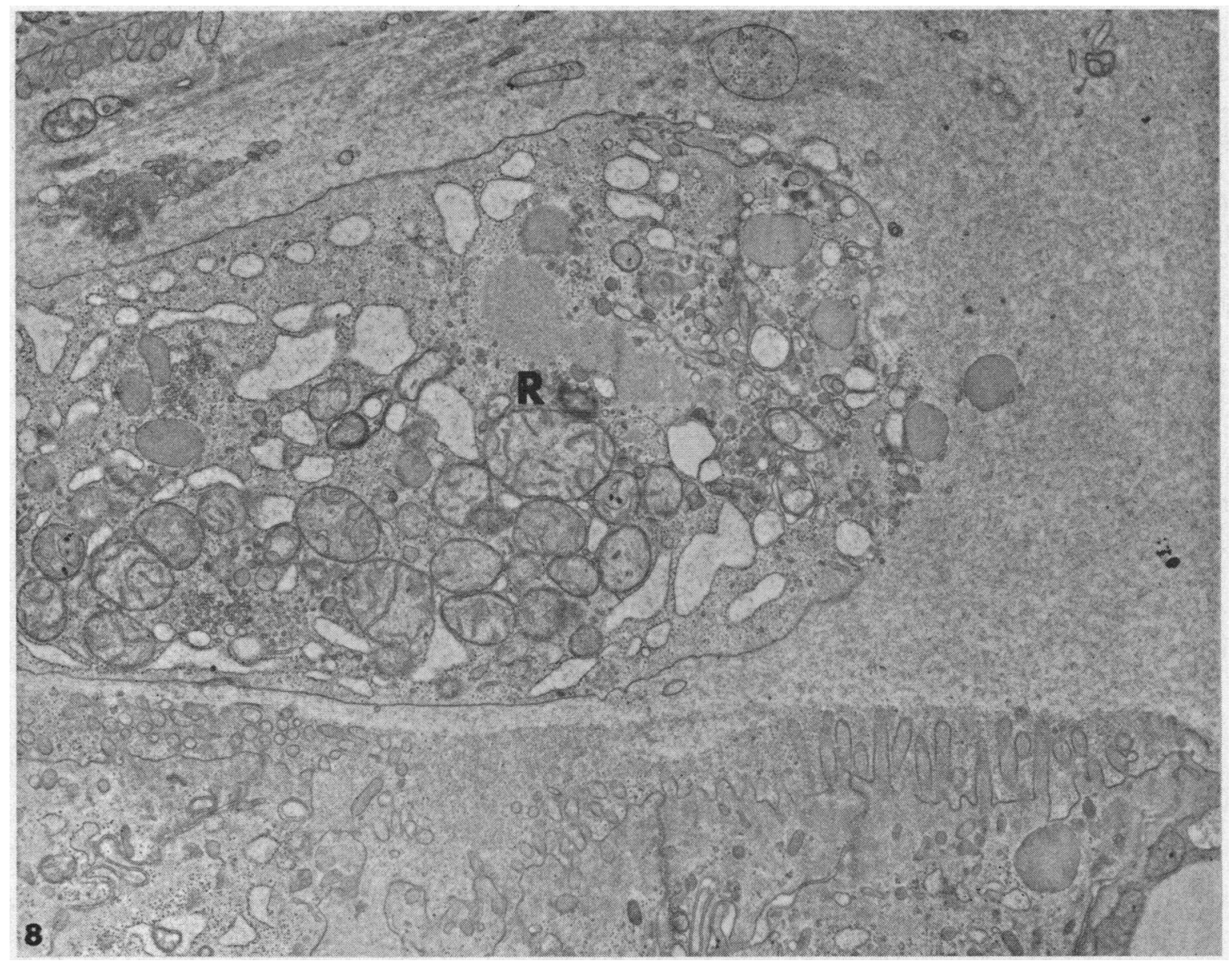

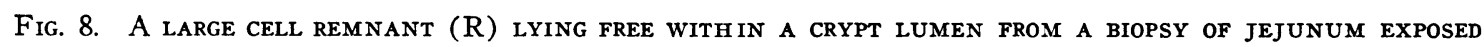
To $2,000 \mathrm{R} X \mathrm{RAY}$. The fine structure of the remnant suggests an epithelial origin. The apical portions of several crypt epithelial cells are seen below. $(14,000 \times$.) 


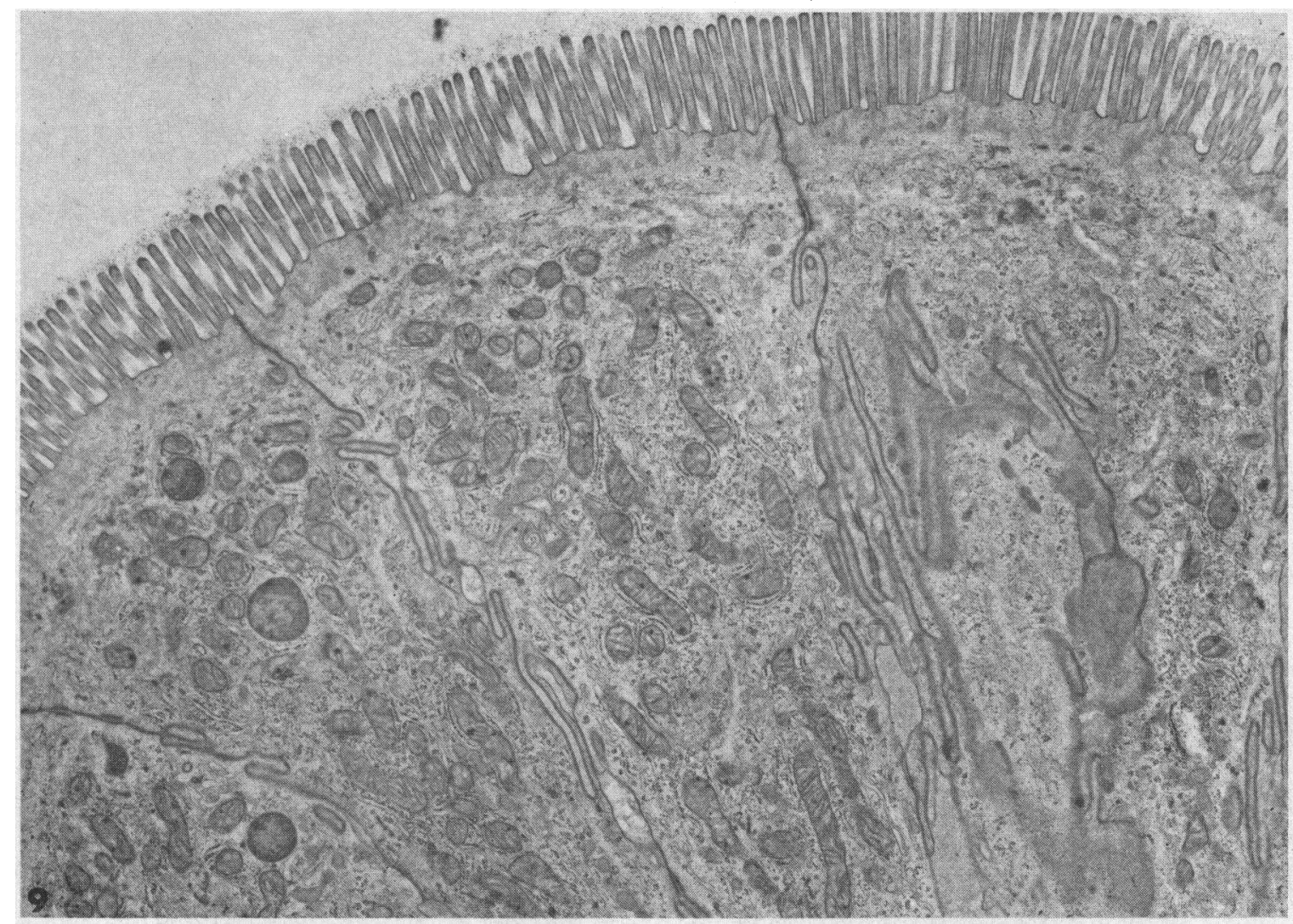

Fig. 9. Apical cytoplasm of NORMal villous abSORPtive CELls from a PRETREatment Biopsy. Note the compact cytoplasm. $(10,000 \times$.)

In all five patients from whom post-treatment biopsies were obtained, recovery of mucosal histology was prompt and complete within 2 weeks after cessation of therapy (Figure $1, \mathrm{~b}$ and $\mathrm{c}$ ). Electron microscopy of biopsies obtained from two patients 2 weeks after cessation of irradiation

TABLE II

Mitoses per 100 crypt sections before, during peak response to, and after recovery from, $X$-ray therapy

\begin{tabular}{cccc}
\hline \hline Patient & $\begin{array}{c}\text { Pretreat- } \\
\text { ment* }\end{array}$ & $\begin{array}{c}\text { During } \\
\text { X ray }\end{array}$ & Recovery* \\
\hline 1 & 105 & 24 & 125 \\
2 & & 40 & \\
3 & & 54 & \\
4 & 86 & 24 & 107 \\
5 & 80 & 22 & 90 \\
6 & 99 & 32 & 102 \\
7 & 105 & 46 & 107 \\
Range & $80-105$ & $22-54$ & $90-125$ \\
Mean & 95 & 35 & 106 \\
& & &
\end{tabular}

* The empty spaces indicate that no biopsy was obtained. also failed to show fine structural abnormalities of either crypt or villous epithelial cells.

Quantitative evaluation of the reduction of the number of mitoses in biopsies from exposed bowel from seven patients is summarized in Table II. The number of mitoses per 100 well-oriented centrally cut crypt sections decreased from a mean of 95 in pretreatment biopsies to a mean of 35 (37\% of control levels) in biopsies obtained during peak histologic response. This was followed by an increase in mitoses to a mean of 106 per 100 crypt sections in biopsies obtained after recovery from $\mathrm{X}$-ray exposure.

In Table III are summarized the results of quantitative evaluation of the epithelial length in these same biopsies by assessing the epithelial length using the modified Chalkley random count method. During peak histologic reaction, there was a mean reduction of epithelial surface length of $43 \%$ compared to control biopsies. Surface length returned 


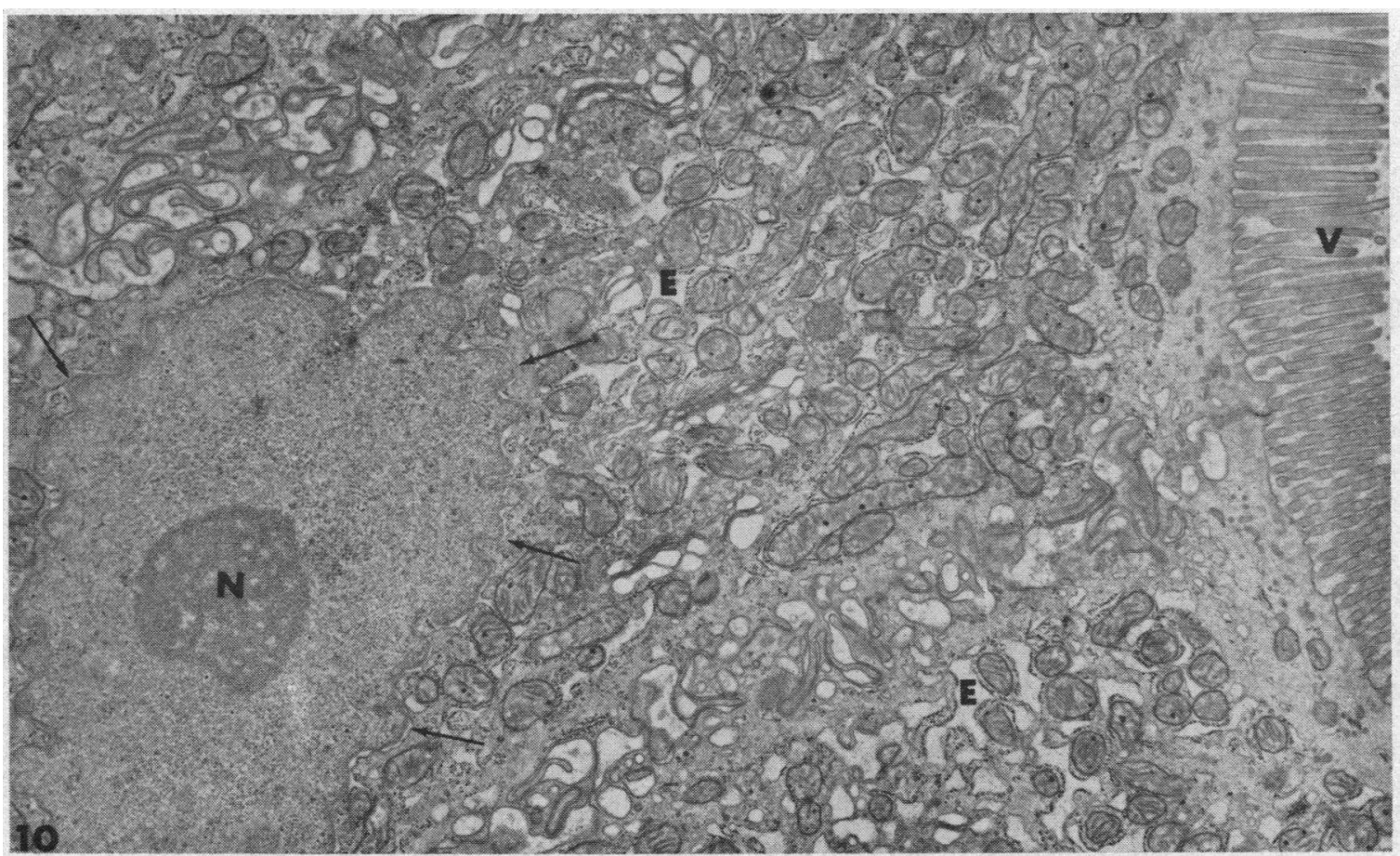

Fig. 10. Villous absorptive cells of a biopsy from the Same patient as Figure 9 after 3,300 R X Ray to THE ABDOMEN. Whereas the microvilli are well preserved, there is dilatation of the endoplasmic reticulum (E) giving the cells a vacuolated appearance. A huge nucleolus (N) and a scalloped nuclear border (arrows) characterize the nucleus. $(10,000 \times$.)

to normal in biopsies obtained 2 weeks or more after cessation of X-ray therapy.

The sequential changes in mitotic activity and surface area observed in the exposed small intestinal mucosa of a patient (no. 6) during the development of and recovery from the mucosal radiation lesion are shown in Figure 11. The number of mitoses per crypt decreased rapidly and was halved within a day after the start of treatment. During the next week, reduction in mitoses became more pronounced and persisted throughout therapy. The reduction of epithelial surface occurred more gradually throughout the course of therapy and was most pronounced toward the end of treatment. When treatment was stopped, return of mitotic activity to normal levels was prompt and was followed by an increase in epithelial surface to normal levels within 12 days. In the other four patients from whom serial biopsies were obtained, mitoses were reduced 26 to $40 \%$ within 3 days after the start of therapy, whereas significant reduction of epithelial length was not noted until the second or third weeks of therapy. In the two other patients from whom biopsies were obtained within 3 days of cessation of therapy, mitoses had returned to pretreatment levels while epithelial length was still reduced. Thus, reduction of mitoses preceded reduction of surface epithelium during therapy, and recovery of mitoses preceded return of epithelial surface to normal when exposure to $\mathrm{X}$ ray was stopped.

\section{TABLE III}

Epithelial counts (surface length) before, during peak histologic response to, and after recovery from, X-ray therapy

\begin{tabular}{cccc}
\hline Patient & $\begin{array}{c}\text { Pretreat- } \\
\text { ment* }\end{array}$ & $\begin{array}{c}\text { During } \\
\text { X ray }\end{array}$ & Recovery* \\
\hline 1 & 147 & 78 & 144 \\
2 & & 85 & \\
3 & 142 & 89 & \\
4 & 120 & 75 & 144 \\
5 & 146 & 83 & 124 \\
6 & 150 & 89 & 148 \\
7 & $120-150$ & $73-89$ & $124-155$ \\
Range & 141 & 81 & 143 \\
Mean & & & \\
\hline
\end{tabular}

* The empty spaces indicate that no biopsy was obtained. 


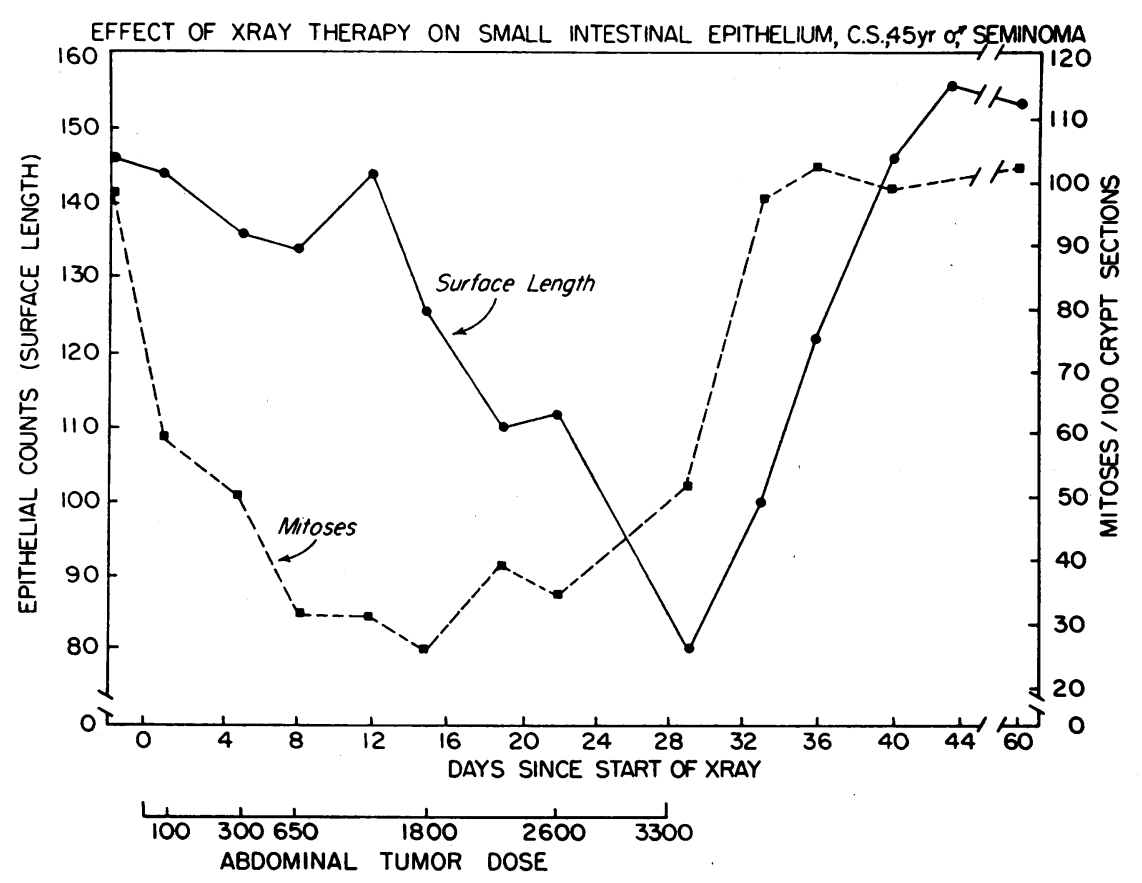

Fig. 11. Sequential changes in mitoses and epithelial surface in the exPOSED SMALl INTESTINe OF PATIENT 6 DURING DEVElopMent OF AND RECOVERY FROM THE MUCOSAL RADIATION LESION.

Mucosal biopsies obtained from two patients (8 and 9) from jejunum distant from the field of irradiation remained morphologically normal throughout therapy. Quantitative evaluation of mitotic activity and epithelial surface by the techniques described above confirmed our histological impression that there was no detectable change in these parameters of mucosal structure in small bowel distant from the X-ray beam during therapy in these two patients.

\section{Discussion}

The histological changes observed in this study were similar to those observed in the small intestine of laboratory animals after exposure to sublethal doses of irradiation (2-5). Similarly, some of the observed fine structural changes (irregularity of the microvilli, mitochondrial swelling) paralleled those seen initially after exposure of mice to a single lethal dose of irradiation (20).

It has been established that the rate of cell turnover of the small intestinal epithelium of man is rapid; complete replacement of the villous epithelium as measured by the migration of thymidine- ${ }^{3} \mathrm{H}$ labeled crypt cells occurs in 5 to 6 days
$(21,22)$. It is also well known that X-ray irradiation interferes with cell division (23).

The first morphologic change in the intestinal epithelium of our patients after exposure to X-ray therapy was a reduction in the number of mitoses in the crypts. This mitotic inhibition persisted until the cessation of therapy. This reduced cell proliferation in the crypts probably resulted in a decreased outflow of cells from the crypts onto the villi to replace those senescent villous epithelial cells shed from the villous tips into the gut lumen. The presence of large epithelial cell fragments in crypt lumina (Figure 8) suggested that damaged cells may also be shed into the gut lumen directly from the crypt epithelium, compounding the shortage of cells available for migration onto the villus. Thus, as exposure to radiation was continued, cell loss from the villous tips exceeded cell replacement from the crypts, the villi shortened, and total epithelial surface decreased (Figure 11, Table III). This decrease in the height of the villi would have been far greater had not the individual epithelial cells increased markedly in width.

Whereas a decrease in epithelial surface is also characteristic of the mucosal lesion of celiac sprue 
(12), the radiation-induced mucosal lesion differs greatly from the sprue lesion. Though the term "villous atrophy" has often been used to describe the sprue lesion (24), true atrophy of the mucosa is not a characteristic feature of sprue. Instead, measurements of the total mucosal thickness in biopsies of patients with severe sprue lesions are often normal (25). Whereas the villi are shortened or absent in sprue, the crypts appear much deeper $(12,25)$ often extending to the surface epithelium. In contrast, the radiation-induced lesion is characterized by true atrophy of the mucosa; not only are the villi shortened, but the crypts are more shallow than those seen in normal biopsies. Furthermore, the number of mitoses in the crypts is increased over normal in sprue (26, 27) suggesting the possibility of more rapid cell proliferation in contrast to the reduced proliferation that follows irradiation exposure.

Biopsies obtained from small bowel outside the field of irradiation appeared normal with the morphological techniques employed in this study. This suggested that the radiation-induced mucosal lesion was limited to the small bowel directly exposed to irradiation at the doses studied. Thus, there was no evidence of an abscopal radiation effect in unexposed bowel such as has been noted in the thymus and spleen of mice after highly localized irradiation to distant portions of the abdomen (28).

Clinical symptoms that could be attributed to irradiation therapy were minimal or absent in our patients. Of the seven patients in whom the irradiation lesion was demonstrated, one gained weight, two lost weight, and the others remained stable during this study (Table I). Vomiting was observed in only one patient who received a total dose of $2,000 \mathrm{R}$ and was probably due to the patient's underlying lymphoma, since it preceded the start of X-ray therapy. Two other patients experienced mild nausea without vomiting while receiving $\mathrm{X}$ ray; none had diarrhea. Whereas studies of small intestinal absorption were not regularly performed in our patients, Patient 6, who received a total dose of $3,300 \mathrm{R}$ was placed on an 80 $\mathrm{g}$ per day fixed fat intake during the last week of $\mathrm{X}$-ray therapy, and a pooled 96-hour stool collection was obtained during the last 4 days of therapy while the patient's radiation-induced lesion was most pronounced (Figures 1b, 11). Despite the marked morphologic abnormalities observed in his biopsies at that time, his coefficient of fat absorption was $94 \%$. This further suggested that the mucosal lesion was limited to the exposed bowel, whereas the remaining small bowel was unaffected, since one would expect detectable steatorrhea if the entire small intestine were involved.

Whereas these findings indicate that dosages of $\mathrm{X}$ ray commonly administered to the abdominal cavity for therapeutic purposes induce a distinct lesion of the mucosa of the small intestine directly exposed to irradiation, there was no indication that $\mathrm{X}$ ray, in the doses studied, resulted in any permanent damage to the small intestinal mucosa. In the five patients studied after the cessation of $\mathrm{X}$-ray therapy, histological recovery of the mucosa was complete within a period of 2 weeks.

The submucosa and muscular coats of small intestine are not adequately sampled by peroral biopsy. Therefore, we cannot exclude the development of a more persistent lesion in the submucosal layers of the small intestine after these doses of irradiation. In fact, infiltration of the submucosa with round cells and suggestive evidence of submucosal edema were regularly seen during peak mucosal reaction to irradiation in those biopsies in which submucosa was present (Figure 1b). That an irreversible lesion beneath the mucosa may occasionally occur has been suggested by the occasional observation of submucosal fibrosis $(6,7)$ and lymphangiectasia (8) years after irradiation.

\section{Summary}

Peroral biopsies were serially obtained from patients before, during, and after abdominal X-ray therapy from small bowel within the irradiated field. Biopsies were studied by light and electron microscopic techniques.

Histological changes included 1) a reduction of mitoses in the crypts to 25 to $51 \%$ of control levels, 2) marked shortening of the villi with a resultant 39 to $48 \%$ reduction of epithelial surface length, 3) megaloblastosis and megalocytosis of epithelial cells, 4) heavy infiltration of the lamina propria with plasma cells and polymorphonuclear leukocytes, and 5) occasional crypt abscess formation.

Electron microscopy further revealed cytologic epithelial cell changes including 1) swelling and dilatation of mitochondria and endoplasmic reticulum, 2) irregular distribution and shortening of 
microvilli, and 3) a scalloped nuclear border and the presence of huge nucleoli.

Histologic recovery of the mucosal lesion was prompt and complete after cessation of therapy; mitoses were normal within 3 days and villi were normal within 2 weeks. Gastrointestinal symptoms were minimal or absent despite the regular development of the mucosal lesion.

Biopsies from small bowel outside of the field of irradiation from two patients remained normal throughout therapy.

These data indicate that extensive morphologic damage of the small intestinal mucosa of man is regularly induced by therapeutic doses of abdominal X-ray therapy. This is associated with surprisingly few symptoms, is rapidly reversible, and appears localized to the bowel in the field of irradiation.

\section{Acknowledgments}

We are grateful to Mrs. Vilja Lorenzsonn, Mrs. Mary Staley, and Mr. Kenneth Groehler for their expert technical assistance.

\section{References}

1. Trier, J. S., and T. H. Browning. Morphologic response of human small intestine to X-ray exposure (abstract). Clin. Res. 1965, 13, 263.

2. Pierce, M. The gastrointestinal tract in Histopathology of Irradiation from External and Internal Sources, W. Bloom, Ed. New York, McGrawHill, 1948, p. 502.

3. Bloom, M. A. Acquired radioresistance of the crypt epithelium of the duodenum. Radiology 1950, 55, 104.

4. Quastler, H., J. P. M. Bensted, L. F. Lamerton, and S. M. Simpson. Adaptation to continuous radiation: observations on the rat intestine. Brit. J. Radiol. 1959, 32, 501.

5. Wimber, D. R., and L. F. Lamerton. Cell population studies on the intestine of continuously irradiated rats. Radiat. Res. 1963, 18, 137.

6. Sauer, W. G. Factitial enteritis : an unusual cause of intestinal obstruction, chronic blood loss or malabsorption syndrome. J. Iowa St. med. Soc. 1960, 50, 1.

7. Viner Smith, K. The malabsorption syndrome. Med. J. Aust. 1958, 2, 255.

8. Greenberger, N. J., and K. J. Isselbacher. Malabsorption following radiation injury to the gastrointestinal tract. Amer. J. Med. 1964, 36, 450.

9. Salvesen, H. A., and M. Kobro. Symptomatic sprue. Acta med. scand. 1939, 102, 277.

10. Brandborg, L. L., C. E. Rubin, and W. E. Quinton. A multipurpose instrument for suction biopsy of the esophagus, stomach, small bowel, and colon. Gastroenterology 1959, 37, 1.
11. Trier, J. S. Morphologic alterations induced by methotrexate in the mucosa of human proximal intestine. I. Serial observations by light microscopy. Gastroenterology 1962, 42, 295.

12. Rubin, C. E., L. L. Brandborg, P. C. Phelps, and H. C. Taylor, Jr. Studies of celiac disease. I. The apparent identical and specific nature of the duodenal and proximal jejunal lesion in celiac disease and idiopathic sprue. Gastroenterology 1960, $38,28$.

13. Chalkley, H. W. Method for quantitative morphologic analysis of tissues. J. nat. Cancer Inst. 1943, 4, 47.

14. Dalton, A. J. A chrome-osmium fixative for electron microscopy (abstract). Anat. Rec. 1955, 121, 281.

15. Luft, J. H. Improvements in epoxy resin embedding methods. J. biophys. biochem. Cytol. 1961, 9, 409.

16. Trump, B. F., E. A. Smuckler, and E. P. Benditt. A method for staining epoxy sections for light microscopy. J. Ultrastruct. Res. 1961, 5, 343.

17. Luft, J. H. Personal communication.

18. Millonig, G. A modified procedure for lead staining of thin sections. J. biophys. biochem. Cytol. 1961, $11,736$.

19. Trowell, O. A. The sensitivity of lymphocytes to ionizing radiation. J. Path. Bact. 1952, 64, 687.

20. Quastler, H., and J. C. Hampton. Effects of ionizing radiation on the fine structure and function of the intestinal epithelium of the mouse. I. Villus epithelium. Radiat. Res. 1962, 17, 914.

21. Lipkin, M., P. Sherlock, and B. Bell. Cell proliferation kinetics in the gastrointestinal tract of man. II. Cell renewal in stomach, ileum, colon, and rectum. Gastroenterology 1963, 45, 721.

22. MacDonald, W. C., J. S. Trier, and N. B. Everett. Cell proliferation and migration in the stomach, duodenum, and rectum of man: radioautographic studies. Gastroenterology 1964, 46, 405.

23. Friedman, N. B. Cellular dynamics in the intestinal mucosa: the effect of irradiation on epithelial maturation and migration. J. exp. Med. 1945, 81, 553.

24. Shiner, M., and I. Doniach. Histopathologic studies in steatorrhea. Gastroenterology 1960, 38, 419.

25. Madanagopalan, N., M. Shiner, and B. Rowe. Measurements of small intestinal mucosa obtained by peroral biopsy. Amer. J. Med. 1965, 38, 42.

26. Padykula, H. A., E. W. Strauss, A. J. Ladman, and F. H. Gardner. A morphologic and histochemical analysis of the human jejunal epithelium in nontropical sprue. Gastroenterology 1961, 40, 735.

27. Yardley, J. H., T. M. Bayless, J. H. Norton, and T. R. Hendrix. Celiac disease. A study of the jejunal epithelium before and after a gluten-free diet. New Engl. J. Med. 1962, 267, 1173.

28. Jansen, C. R., V. P. Bond, K. R. Rai, and S. W. Lippincott. Abscopal effects of localized irradiation by accelerator beams. Ann. N. Y. Acad. Sci. 1964, 114, 302. 